\title{
Limiting risks by curtailing rights: a response to Dr Ryan
}

Steven Luttrell and Ann Sommerville Geriatric Department, Whittington Hospital, London and Medical Ethics Department, British Medical Association, Tavistock Square, London.

\begin{abstract}
It has been argued that the inherent risks of advance directives made by healthy people are disproportionate to the potential benefits, particularly if the directive is implementable in cases of reversible mental incapacity. This paper maintains that the evidence for such a position is lacking. Furthermore, respect for the principle of autonomy requires that individuals be permitted to make risky choices about their own lives as long as these do not impinge on others. Even though health professionals have an obligation to try and ensure that patients have appropriate information about possible future treatment options, they cannot predict and describe every eventuality but nor can they disregard firm decisions knowingly made on the basis of incomplete information by competent adults. To attempt to do so would be to reinstate notions of medical paternalism which are contrary to current public expectations.
\end{abstract}

Decisions about life-sustaining medical treatment should really be left to doctors. That is the core message of "betting your life" by Dr C J Ryan.' Although he focuses on only one type of decision when the patient's mental incompetence is potentially reversibie - the implication is that healthy people cannot validly appreciate the dimensions of the risk involved when they seek to limit in advance the scope of their own medical treatment. The danger of such miscalculation is said to be so profound that their right to take the risk must be curtailed for their own good. The general argument is not new. As the House of Lords Select Committee on Medical Ethics noted: "Disabled individuals are commonly more satisfied with their life than able-bodied people expect to be with the disability. The healthy do not choose in the same way as the sick". 2 But does this mean healthy people are to be deprived of the opportunity to make the attempt?

Some of the existing criticism of advance decision-making has been preoccupied with personal

\section{Key words}

Advance decision-making; autonomy; living will; continuity of identity; paternalism. identity and the continuity of mind and mental state as the important criteria. According to such arguments, the rupture caused by loss of competence is so great that it makes nonsense of the concept of personal continuity. A competent individual is not making advance decisions for herself but for the future relict of who she once was. Dr Ryan's argument is a variation on this theme and seeks to prove that in advance of disability, people are in such a totally different mind-set that they are "likely to grossly under-estimate their desire for medical intervention should they become ill".

We do not agree with Dr Ryan's view that advance directives dealing with situations where the deterioration in mental capacity is potentially reversible should be abolished and take issue with him on the following points:

(1) His argument hinges on the notion that people are likely to under-estimate substantially their desire to have medical intervention should they become ill. The evidence for this is not convincing. Emanuel et al following a prospective study of 495 HIV-positive or oncology out-patients and 102 members of the public concluded that most people made moderately stable treatment choices and that recent hospitalisation did not decrease that stability. ${ }^{3}$

Even if it is the case that in general the sick do not make the same choices as the healthy, there is evidence that this does not apply to people who have completed an advance directive. Although Danis et al found that patients who were hospitalised one or more times between baseline and follow-up interviews were more likely to change their choices and desire more treatment, patients who had a living will were more likely to maintain stable preferences. Indeed, patients who had living wills and chose the least amount of care at their initial interview had extremely stable preferences $(96$ per cent unchanged). ${ }^{4}$

There appears to be little evidence that healthy people consider making treatment decisions in advance. Even in the United States, where living wills have been in existence much longer than in Britain, there is a wide disparity between the large percentage of people who indicate a desire to die without heroic measures and the small percentage 
who have made advance directives. ${ }^{5}$ The scant UK evidence $^{6}$ supports American findings that interest in living wills is primarily shown by people who are educated, articulate and already have a diagnosis. (In the USA, the obligation for hospitals to raise the subject of advance decision-making arose only with patients who were checking in for treatment and therefore, by definition, were not a healthy population.) Part of the increased interest in this mechanism in the UK has been as a result of a small but well-informed population of HIV-positive patients witnessing the terminal treatment of friends and partners. Indeed, one of the limitations of advance statements is their lack of ready accessibility to people with differing levels of education, experience and literacy.

(ii) Dr Ryan states that it is an accepted principle that one cannot properly exercise one's autonomy if one is not in possession of all available information that might influence one's decisions and that a patient's consent to a procedure is only valid if she has been informed of all the risks and consequences. We take issue with this view. It implicitly denies the option of consciously deciding from a knowingly incomplete knowledge base and the option to decide validly to allow another person to decide on one's behalf. It is not necessarily obligatory for an individual to know each and every one of the risks implicit in a course of action. Indeed, if this were the case, no person could ever make a valid decision. As human beings, our motivation is often intuitive or emotional as well as cognitive and we sometimes exercise autonomy by choosing not to know or at least not to recognise the full import of our actions. It is arguably not necessary to examine all the implications in order for a person to be clear that she does not want to go on living indefinitely with a restricted range of competency or mobility, even if some small improvement is possible. If applied to other spheres of medicine, Dr Ryan's principle would mean that people cannot make valid decisions about childbearing without taking account of potentially available genetic information or pre-natal testing.

Arguably, therefore, it cannot be assumed that in real life, people who make advance refusals want to know everything or, if having chosen not to be fully informed of every detail, are incapable of understanding the implications of their decision. Nevertheless, the Code of Practice on Advance Statements, published by the British Medical Association, sees health professionals as obliged to make all appropriate efforts to raise patients' awareness at the drafting stage about the risks and disadvantages, as well as the benefits, of advance statements. ${ }^{7}$ As a matter of law in the UK, a patient's consent to a procedure is valid if he understands in general terms the nature of the intervention. There is no legal obligation to explain all the risks and benefits. ${ }^{8}$

(iii) Even if people do make unwise choices, we believe that this should not be used as a reason to curtail their autonomy. Society generally recognises that individuals sometimes make bad or risky choices in the way they shape their lives. In our society, the libertarian. legacy of Mill, however, assumes that individual choices should be permitted, unless they impinge on the rights of others. Mill's famous dictum was that "the sole end for which mankind are warranted, individually or collectively, in interfering with the liberty of action of any of their number is self-protection" and that an individual "cannot rightfully be compelled to do or forbear because it will be better for him to do so, because it will make him happier, because in the opinions of others to do so would be wise or even right". 9 So, does it damage the fabric of society or the rights of other people to allow Jehovah's Witnesses, for example, the right to refuse in advance the administration of blood products in all circumstances, even when their condition is curable? Or should they, as Dr Ryan suggests, be forcibly treated and only then "their opinions regarding future treatment be sought again now that they are in the scenario that they had previously only imagined"?

\section{Common sense}

It is trite to observe that people's views change with their circumstances. The philosopher, Parfit, for example, discussing different stages of individual development, talks about "my most recent self", "one of my earlier selves" and "one of my distant selves"; each of these showing a different degree of psychological connectedness with the present self. ${ }^{10}$ From a practical perspective, would this mean that greater weight must automatically be attached to an advance directive made comparatively recently by an individual who is still more or less the same self? Common sense would seem to support such a view even if the individual was completely healthy when making the directive and now is in an altered psychological state. Simply acknowledging varying degrees of psychological continuity or disparity with regard to former and future selves does not answer the question of whether it is morally correct for subsequent selves to be treated in contravention of an advance directive reflecting their former interests.

(iv) We believe that a retreat to medical paternalism is not a practical option in societies increasingly aware of patient charters and consumer rights. Many forms of advance directives offer the drafter a choice of specifying personal instructions and/or nominating a proxy to decide. American surveys show that the option most commonly chosen is for people to select decision-making by a family member or other proxy despite the evidence of a variable correlation between the judgments of nominated proxy decision-makers and the patients' own prior wishes. ${ }^{11}$ One study indicated that of 104 patients with life-threatening illness who were offered advance directives, 69 took up the offer and most 
asked for non-aggressive treatment if "the burdens of treatment outweigh the expected benefits". None, however, gave any other personal instructions, ${ }^{12}$ although evidence suggests that proxies are more likely than patients themselves to opt for life-prolonging treatment, ie, to support more conservative choices than the individual would have made if competent and in that situation. ${ }^{13}$

Dr Ryan contests one specific type of advance directive on grounds of utility and autonomy. $\mathrm{He}$ argues that it is contrary to utility to permit people to die when their lives could be prolonged and their condition improved. This might be true if utility were a matter of simply prolonging life rather than also a question of maximising happiness and choice and reducing misery, including the misery of families who may see their relative being resuscitated contrary to an informed and competent advance refusal.

\section{Two autonomies}

Nor is autonomy a simple matter. When an individual is conscious but mentally incapacitated, in Dworkin's view, "two autonomies are in play: the autonomy of the demented patient and the autonomy of the person who became demented. These two autonomies can conflict, and the resulting problems are complex and difficult". ${ }^{14}$ Of course, some philosophers solve this by attributing no autonomy to the demented person and recognising the "residual interests" of the previously competent individual as paramount. A range of psychological and philosophical questions arise here about our ability to decide now life and death matters for the people we will be in the future when some part of what makes us the individuals we are - our awareness of ourselves, our past and continuity - has been lost. Dworkin seems to support Dr Ryan's approach in seeing the competent person who makes the anticipatory decision as fundamentally different from and other to the incapacitated individual who lives out (or not) the consequences of the decision. It is widely accepted that individuals can only make advance directives for "themselves". A person who becomes severely mentally disordered, however, is in some sense no longer "herself". Nevertheless, despite the lack of continuity, the former, competent "self" should arguably still retain moral rights about how the later, incompetent self is treated. ${ }^{15}$ Even if acknowledged as being not quite the same person, the claim of the competent to decide on behalf of the later incompetent self still appears stronger than the claims of other players, especially bearing in mind the above-mentioned tendency for proxy decisionmakers to choose options inconsistent with the individual's own values.

There is a danger that health professionals and nominated proxies will not take full account of the complex mixture of reasoning which leads some people to choose to forego treatment even in situations where medicine can offer them an extension of life. Although doctors' decisions about lifesaving treatment correlate with their own estimate of subsequent quality of life, they significantly underestimate their elderly patients' quality of life compared with the views of the patients themselves. ${ }^{16}$ For some people, medical views of quality of life or possibility of improvement may not be a central issue. Just as Dr Ryan points out that it is difficult for healthy people convincingly to imagine themselves with disability, so it is often hard for the young or middle-aged to envisage that there may be a stage when we have simply lived long enough and the burdens of further treatment no longer outweigh the benefits. We may then wish to opt out even at the N risk of potentially missing out on a slightly prolonged ? lifespan.

(v) We do not agree that advance directives for conditions of temporary mental incapacity should be less valid than advance directives for conditions of permanent mental incapacity. We question the logic of such a distinction. Dr Ryan concedes that his argument does not apply where loss of mental capacity is permanent. He distinguishes this situation as there "will be no possibility of the person recovering to give carers a more accurate report of her current desire for treatment"1 and therefore they should be guided by an existing living will. He recognises that an accurate report of individual $\stackrel{\perp}{\perp}$ wishes is of value and therefore should be respected. $\overrightarrow{\vec{A}}$ If, however, a Jehovah's Witness, for example, 3 repeatedly states that under no circumstances does he want a transfusion with blood products, Dr Ryan would urge us to ignore this directive if mental incapacity is temporarily impaired. There is no logical reason why the situation where mental incapacity is temporary should be treated in a different way from the situation where the incapacity is permanent. We feel that in both cases an appropriately worded advance directive should be equally applicable.

\section{Information-sharing}

(vi) Even if Dr Ryan's arguments are accepted, we do not agree that "there is the possibility of large numbers of people dying when they would not have $c$ wanted to" although it may be that some will die when doctors would prefer to keep them alive. Doctors hostile to the concept of advance decisionmaking can limit or otherwise influence patients'? choices. The acceptance or refusal of treatment is highly dependent on the amount and manner of $\frac{\vec{D}}{\mathbb{D}}$ information-sharing about the treatment options. ${ }^{17} \frac{\mathrm{O}}{\mathrm{Q}}$ Discussion with elderly out-patients about limiting $\stackrel{\mathbb{}}{\varrho}$ treatment rarely occurs ${ }^{18}$ and in Emanuel's survey of patient and public opinion, the lack of physician ini- $\Omega$ tiative was the most frequently mentioned perceived barrier to the making of advance directives. In this survey of 405 out-patients and 102 members of the 
public, 93 per cent of the former and 89 per cent of the latter claimed to desire advance directives but considered their doctors to be reluctant. ${ }^{19}$ Yet it is to be strongly advised that advance directives are only made in conjunction with advice and information from health professionals. ${ }^{20}$

Dr Ryan's arguments only apply to advance directives which withhold consent to treatment where there has been a temporary loss of mental capacity. We agree that the greatest value of advance directives is their use in situations where the loss of mental capacity is not reversible, such as in cases of dementia, chronic stroke or chronic brain injury due to trauma.

Nevertheless, we refute his thesis that large numbers of people will die unnecessarily since we believe it unlikely that many people will draft advance directives specifically indicating that they would not want treatment if they were to suffer temporary mental incapacity. Examples of common clinical situations where a reduction in mental capacity is potentially reversible include the acute confusional state in an older person, the early phase of recovery from an acute stroke, and the early stage of recovery from head trauma and psychiatric illness. We agree that the advance directive is of more limited application in these situations as it may be very difficult to envisage what degree of recovery will occur. Certainly, with respect to mental illness, if a patient is detained under a section of the Mental Health Act 1983, treatment under the Act will override any refusal of treatment of mental disorder set out in an advance directive.

If one examines the standard forms for advance directives in the UK, many emphasise that for the decision to be implementable the deterioration in mental capacity must be considered permanent or where life is nearing its end due to a terminal physical illness. People may draft their decisions in any form but many use standard documents which direct attention to irreversible conditions. One of the most common living wills, the Terrence Higgins Trust model, is not unique in allowing drafters the option of choosing to have all available treatment as well as refusing interventions in three situations:

- When there is a life-threatening illness from which there is no likelihood of recovery and it is so serious that life is nearing its end;

- When mental functions become permanently impaired with no likelihood of improvement and the impairment is so severe that the drafter does not understand what is happening and medical treatment is needed to keep him alive;

- When the drafter is permanently unconscious with no likelihood of regaining consciousness. ${ }^{21}$

Dr Ryan's argument is based on the fact that the sick do not make the same choices as the healthy. $\mathrm{He}$ does not point out, however, that in many instances advance directives are made by people who are already sick. Indeed, the mechanism is probably most useful for those people who have already been diagnosed as having a chronic illness for which there is no adequate curative treatment and where there is likely to be a predictable pattern of deterioration, for example, patients with AIDS or dementia. Moreover, even if an advance directive is made while the drafter is healthy, he or she will often have the opportunity of revoking or changing it when illness occurs as long as mental capacity is retained.

\section{Conclusion}

For the reasons outlined in this paper, we maintain that advance directives refusing treatment during periods of temporary incapacity should be respected. We acknowledge, however, that there are difficulties for healthy people trying to make decisions for future events. It is important that patients are made aware of these difficulties and not discouraged by medical reluctance to discuss the matter so that they draft directives in isolation. Emanuel found that those patients who had discussion with their physicians made the most stable decisions. ${ }^{3}$ We would therefore urge any person making an advance directive about medical therapy to discuss the directive with a medical practitioner.

\section{Disclaimer}

The views in this paper are the personal opinions of the authors and do not necessarily reflect any views or policies of the BMA.

Dr Steven Luttrell, MBChB, BSc, MRCP, Barrister, is Senior Registrar in the Department of Health Care for Older People, Whittington Hospital, London and Ann Sommerville, $M A$, is Head of the Medical Ethics Department, British Medical Association, London.

\section{References and notes}

1 Ryan J. Betting your life: an argument against certain advance directives. Fournal of Medical Ethics 1996; 22: 95-9.

2 House of Lords Select Committee on Medical Ethics. Report from the Select Committee on Medical Ethics. London: HMSO, 1994: 1: 41.

3 Emanuel L, Emanuel E, Stoeckle, et al. Advance directives, stability of patient's treatment choices. Archives of Internal Medicine 1994; 154: 209-17.

4 Danis M, Garret J, Harris R, et al. Stability of choices about life sustaining treatments. Annals of Internal Medicine 1994; 120: 567-73.

5 Menikoff JA, Sachs GA, Seigler M. Beyond advance directives: health care surrogate laws. New England Fournal of Medicine 1992; 327: 1165-9.

6 Meadows P. Use of living wills in HIV infection and AIDS. Lancet 1994; 334: 1509. Calvert GM. The completion of living wills: an examination of the demographics, completion and issues raised by the living will. London: Terrence Higgins Trust, 1994. Schlyter C. Advance directives and AIDS: an empirical study of the 
interest in living wills and proxy decision making in the context of HIVIAIDs care. London: Centre of Medical Law and Ethics, Kings College, 1992.

7 Sommerville A. Advance statements about medical treatment. London: BMJ Publishing Group, 1995: 23.

8 Sidaway $v$ Board of Governors of the Bethlem Royal Hospital and the Maudsley Hospital [1985] AC 871.

9 Mill JS. On liberty. London: Parker and Son, 1859: 68.

10 Parfit D. Personal identity. In: Honderich T, Burnyeat M, eds. Philosophy as it is. Harmondsworth: Pelican, 1979: 186-211.

11 For example see Seckler AB, Meier DE, Mulvihill M, Cammer Paris BE. Substituted judgement: how accurate are proxy predictions? Annals of Internal Medicine 1991; 115: 92-8. Ouslander JG, Tymchuk AJ, Rahbar B. Health care decisions among elderly long care residents and their potential proxies. Archives of Internal Medicine 1989; 149: 1367-72. Emanuel BJ, Emanuel LL. Proxy decision making for incompetent patients: an ethical and empirical analysis. Fournal of the American Medical Association 1992; 267: 2067-71.

12 Schneiderman L, et al. Effects of offering advance directives on medical treatments and costs. Annals of Internal Medicine 1992; 117: 599-606.

13 See reference 11: Seckler AB, et al.
14 Dworkin R. Life's dominion. London: Harper Collins, 1993.

15 Sommerville A. Are advance directives the answer? In: Maclean S, ed. Death, dying and the law. Aldershot: Dartmouth Press, 1996.

16 Uhlmann RF, Pearlman RA. Perceived quality of life and preferences for life sustaining treatment in older adults. Archives of Internal Medicine 1991; 151: 495-7.

17 Ainslie A, Beisecker A. Changes in treatment decisions by elderly persons based on treatment descriptions. Archives of Internal Medicine 1994; 154: 2225-33. Malloy TR, Wigton RS, Meeske J, Tape TG. The influence of treatment descriptions on advance directive decisions. Fournal of the American Geriatric Society 1992; 40: 1255-60.

18 Goold SD, Arnold RM, Siminoff LA. Discussion about limiting treatment in a geriatric clinic. Fournal of the American Geriatric Society 1993; 41: 277-81.

19 Emanuel LL, Barry MJ, Stoeckle JD, et al. Advance directives for medical care - a case for greater use. New England fournal of Medicine 1991; 324: 889-95.

20 Mower WR, Baraff LJ. Advance directives, effect of type of directive on physicians' therapeutic decisions. Archives of Internal Medicine 1993; 153: 375-81.

21 Living will drawn up by Terrence Higgins Trust and King's College Centre for Medical Ethics and Law.

\section{News and notes}

\section{Bioethics and Biolaw}

An international conference is to be held in Copenhagen, Denmark 29 May-1 June 1996 under the patronage of UNESCO. The conference is organised by The Centre for Ethics and Law, The Danish Council of Ethics and Philosophical Forum. Conference venue: The Danish
Parliament Building, Christiansborg (Copenhagen).

Secretariat for the conference: Centre for Ethics and Law, Symbion Science Parc, Fruebjergvej 3, 2100 Copenhagen, Denmark. Tel: +45-39.17.98.58 - Fax: +45-39.17.98.57.

\section{News and notes}

\section{European Bioethics Seminar}

The fifth European Bioethics Seminar, entitled Health Care Issues in Pluralistic Societies, will be held from August 5-9, 1996, at Nijmegen, the Netherlands. The seminar is organised by the International Program in Bioethics Education and Research. Prominent bioethics scholars from different countries will provide participants with both a formal and practical understanding of contemporary bioethics issues.
Special attention will be paid to European traditions in health care ethics. All lectures and plenary sessions will be in English.

For more information: Mrs J C M Felet-de Haard, Catholic University of Nijmegen, 232 Dept of Ethics, Philosophy \& History of Medicine, PO Box 9101, $6500 \mathrm{HB}$, Nijmegen, The Netherlands. Tel: [31] (0)24-3615320/Fax: [31] (0)24-3540254. 